\title{
COMO PENSAR O DIREITO NA ATUALIDADE? DIÁLOGOS INTERDISCIPLINARES E TRANSDISCIPLINARES ENTRE DIREITO, CULTURA, RELIGIÃO E UTOPIAS NOS MOVIMENTOS SOCIAIS E CULTURAIS ${ }^{1}$
}

\author{
[How to approach the legal framework in the current scenario? \\ Interdisciplinary and transdisciplinary dialogues amongst Law, Culture, \\ Religion and uthopias in social and cultural movements]
}

\author{
NOLI BERNARDO HAHN ${ }^{2}$ \\ ROSÂNGELA ANGELIN³
}

\begin{abstract}
Resumo
Através de uma análise de conceitos filosóficos e de abordagens socioantropológica e jurídica de perspectivas interdisciplinar e transdisciplinar, neste artigo procura-se refletir acerca da seguinte questão: Como inter-relacionar Direito, cultura, religião e movimentos sociais a partir de uma visão paradoxal, dialética e complexa da vida que possibilite noções de justiça que combatam violências, inferiorizações e discriminações e, ao mesmo tempo, motivem vivências e experiências de utopias que fortaleçam relações humanas de superação de uma cultura de injustiças? Os estudos denotam que a humanidade é de condição terrena e linguística e aponta-se que a linguagem integra forças vitais paradoxais, dialéticas e complexas que possibilitam o surgimento de sonhos, de utopias e de uma pluralidade e diversidade de formas humanas de se viver. Tal entendimento é condição necessária para se conceber um Direito que integre como horizonte teleológico uma justiça em que não se discrimine, inferiorize e gere violências, além de impulsionar as pessoas a acreditarem em utopias
\end{abstract}

\footnotetext{
1 Este artigo é resultado de pesquisas e debates realizados a partir de dois Projetos de Pesquisa institucionalizados na Instituição onde os autores são pesquisadores. Num dos Projetos pesquisam-se interfaces entre Direito, Cultura e Religião; noutro Projeto, as pesquisas integram os Movimentos Sociais e Culturais. Ambos os projetos vinculam o tema da Sociedade Complexa e Multicultural. Faz-se menção de agradecimento ao Grupo de Pesquisa “Teologia Pública no Contexto Latino-americano", liderado pelo prof. Dr. Rudolf von Sinner (EST - São Leopoldo, Brasil), atualmente com sede na PUCPR, grupo de pesquisa no qual este artigo foi debatido entre os pesquisadores integrantes e recebeu contribuições significativas para o seu desenvolvimento.

2 Professor Permanente do PPGD da URI - Campus de Santo Ângelo, RS, Brasil; Departamento de Ciências Humanas e Ciências Sociais Aplicadas. nolihahn@san.uri.br

3 Professora Permanente do PPGD da URI - Campus de Santo Ângelo, RS, Brasil; Departamento de Ciências Sociais Aplicadas. rosangelaangelin@yahoo.com.br
} 
Noli Bernardo Hahn \& Rosângela Angelin: Como pensar o direito na atualidade? Diálogos interdisciplinares e transdisciplinares entre direito, cultura, religião e utopias nos movimentos sociais e culturais

neste horizonte de justiça, sonhos despertados em processos educativos de subjetivação e fortalecidos em Movimentos Sociais e Culturais.

Palavras-chave: Direito, Cultura e Religião; Hermenêutica; Movimentos Sociais; Diálogos transdisciplinares

\begin{abstract}
Through a analysis of philosophical concepts and interdisciplinary and transdisciplinary socioantropological and juridical approaches, this article seeks to think on the following question: how to interrelate Law, culture, religion and social movements from a paradoxical, dialectical and complex vision of life which enables notions such as of justice that combats violence, underlings and discrimination, and at the same time, motivates experiences of utopias that strengthen human relationships to overcome a culture of injustice? The studies denote that humanity is of an earthly and linguistic condition, and it is pointed out that language integrates paradoxical, dialectical and complex vital forces that enable the rise of dreams, utopias and the plurality and diversity of human ways of living. Such understanding is a necessary condition to conceive a Law that integrates, as a teleological horizon, a justice in which discrimination, underling and generation of violence are not accepted, in addition to promote people to believe in utopias in this horizon of justice where dreams awakes in educational processes of subjectivity and strengthened in Social and Cultural Movements.
\end{abstract}

Keywords: Law: Culture and Religion; Hermeneutics; Social Movements; Transdiciplinary Dialogues

DOI: $10.7764 / R L D R .10 .127$ 
Noli Bernardo Hahn \& Rosângela Angelin: Como pensar o direito na atualidade? Diálogos interdisciplinares e transdisciplinares entre direito, cultura, religião e utopias nos movimentos sociais e culturais

\section{INTRODUÇÃO}

Como pensar o Direito na atualidade? Que matrizes teóricas são imprescindíveis para se pensar uma legislação que possa corresponder a uma noção de justiça em que não haja inferiorizações, discriminações e violências nas relações entre seres humanos e, inclusive, nas relações entre a natureza e os humanos? Neste artigo propõe-se argumentar que a paradoxalidade ${ }^{4}$, a dialeticidade ${ }^{5}$ e a complexidade ${ }^{6}$ representam três concepções filosóficas paradigmáticas necessárias para se desenvolver uma noção de justiça que emerge, com muita ênfase, a partir da consciência científica sobre linguagem ${ }^{7}$ e meio ambiente ${ }^{8}$, nos últimos séculos. Vinculado a esta reflexão, apontam-se algumas notas sobre conexões possíveis entre Direito, Cultura e Religião, interfaces possíveis de se conceber exatamente

\footnotetext{
${ }^{4}$ Esta categoria de compreensão provém da noção de Filosofia Pós-estruturalista, especialmente a partir da obra de Jacques Derrida (2000; 2002; 2005; 2006).

${ }^{5}$ Ao longo do texto, a noção Hegeliana e Marxista de Dialética perpassa a reflexão. Para compreender esta perspectiva, uma síntese pode ser encontrada em: STOERIG, Hans Joachim. História geral da Filosofia. Petrópolis: Vozes, 2008, p. 395-434.

${ }^{6}$ Leituras e pesquisas de obras de Edgar Morin (1996, 1999, 2001 e 2009) foram fundamentais para introduzir esta categoria neste artigo.

${ }^{7}$ As pesquisas, em Filosofia, especialmente desde fins do século XIX e em todo o século XX, na área da Linguagem, construíram uma consciência de que nós humanos, além da casa terrena que nos acolhe, possuímos uma casa linguística na qual movemos nossas vidas. Nesta perspectiva filosófica podem ser lembrados todos que desenvolveram o pensamento hermenêutico. Em relação à hermenêutica, pode-se citar Friedrich Schleiermacher (2005), Martin Heidegger (2016), Hans-Georg Gadamer (1998), entre outros. A obra de RUEDELL, Aloísio. Hermenêutica - Da necessidade de interpretar para um modo de pensar. Ijuí: Unijuí, 2016, consiste numa pesquisa muito relevante para se constituir uma consciência da dimensão linguística que os humanos somos.

${ }^{8}$ A noção de Ecologia Integral consiste numa consciência de vivência e concepção ecológicas desenvolvida a partir das conclusões científicas das últimas décadas. A Ecologia Integral supera a noção científica em que se concebia o conhecimento inerente a uma racionalidade instrumental cartesiana, desde a que o sujeito instrumentalizava o objeto. Nesta concepção científica, a natureza vista como objeto pelo sujeito era instrumentalizada para os fins racionais do sujeito humano. A Ecologia Integral insere a natureza na relação sujeito-sujeito com o humano e faz entender a Terra como a Casa Comum em que não se possa dissociar o sujeito humano de toda a vida sistêmica que o cosmos representa. Estamos todos integrados num grande e único sistema vital. Um texto relevante e pertinente a esta temática é a Encíclica do Papa Francisco, editada em 2015 (PAPA, 2015). Outro texto, um artigo atual e de reflexão pertinente à temática referida, é a reflexão publicada por CERVI, Jacson Roberto; HAHN, Noli Bernardo. A terra pede paz - a emergência do paradigma do cuidado e a superação do paradigma da conquista. In: Revista Internacional de Direito Ambiental, Caxias do Sul: Plenum, n. 15, p. 95-116, set/dez 2016.
} 
Noli Bernardo Hahn \& Rosângela Angelin: Como pensar o direito na atualidade? Diálogos interdisciplinares e transdisciplinares entre direito, cultura, religião e utopias nos movimentos sociais e culturais

pelas concepções interdisciplinar e transdisciplinar que transbordam do pensamento paradoxal, dialético e complexo. Da mesma forma, argumenta-se, neste artigo, que as três concepções filosóficas mencionadas acima, quando integradas na sociedade e internalizadas culturalmente são capazes de propiciar e despertar sonhos e utopias por uma humanidade em que não se reproduza discriminações, injustiças, violências e inferiorizações. Tais utopias e sonhos, em parte, já vivenciados nos movimentos sociais, mas por estes principalmente despertados, motivados e buscados..$^{9}$

Ciência jurídica, estudos culturais e ciências da religião/teologia são três campos epistemológicos com suas especificidades teóricas e metodológicas. Neste artigo, porém, acentua-se uma metodologia, entendendo por esta categoria de compreensão um caminho ('odós = caminho) que evidencia a possibilidade de se pensar um Direito, que se origina de um mundo de complexidades, dialeticidades e paradoxalidades em que se possa estabelecer e apontar conexões e interfaces entre Direito, cultura e religião, e apontar incidências e relações com a temática dos sonhos utopicamente sonhados e, em algumas dimensões, já experimentados localmente, a partir de vivências em movimentos sociais. ${ }^{10}$

A ciência moderna, de perspectiva e fundamento cartesiano, acentua a separação dos conhecimentos. Normalmente, as pessoas recebem uma formação acadêmica baseada na dissociação e não na associação de saberes. A interdisciplinaridade e a transdisciplinaridade são perspectivas críticas à lógica de construção de conhecimentos, que tinham como finalidade última a formação de especialistas que conheciam profundamente

\footnotetext{
${ }^{9}$ Neste artigo, não se foca num problema ou num tema específico latino-americano, no entanto a ótica teórica possibilita, a seu curso, integrar e refletir contextos latino-americanos, entendendo contextos como experiências históricas e socioculturais de povos localizados. Mesmo que o foco é global e genérico, a perspectiva latino-americana poderá deduzir-se da concepção teórica que perpassa o artigo.

${ }^{10}$ Enfatiza-se novamente que, nesta reflexão, não se tematiza uma experiência específica de perspectiva latinoamericana, porém há inúmeras experiências que poderiam ser lembradas das lutas pela liberdade que se sucederam e continuam acontecendo em terras latino-americanas. Genericamente, lembram-se as lutas de superação de relações coloniais entre países colonizadores e países colonizados; as lutas contra a escravidão e o racismo; as lutas em defesa da República e da democracia; as lutas, especialmente, pelos direitos civis, culturais e sociais; as lutas históricas em defesa dos direitos humanos.
} 
Noli Bernardo Hahn \& Rosângela Angelin: Como pensar o direito na atualidade? Diálogos interdisciplinares e transdisciplinares entre direito, cultura, religião e utopias nos movimentos sociais e culturais

sua área, sem necessariamente entender das incidências práticas de suas reflexões e de seus inventos sobre outras áreas de saber.

Realizar estudos e pesquisas de interfaces epistêmicas não é uma tarefa fácil. Uma razão da dificuldade está na cultura acadêmica impressa durante séculos. A matriz teórica sobre a que se alicerça a separação de conhecimentos foi inculturada em vivências acadêmicas nos corredores das universidades dos últimos séculos. Tornou-se cultura separar, dissociar, desintegrar e fragmentar o conhecimento.

Muitas são as razões do surgimento das perspectivas inter e transdisciplinares. Uma razão a se apontar é a consciência da fragmentação da vida propiciada pela matriz teórica dissociativa. A consciência integrativa da vida, despertada especialmente na segunda metade do século XX, se mostra como uma reação ao esfacelamento, à desintegração e à fragmentação causadas pelo entendimento de que, para explicar e compreender, é necessário separar. Importante ressaltar nessa introdução, em função da reflexão que se faz ao longo do artigo, de que a consciência integrativa da vida se motiva a partir de muitas razões, porém, a consciência antropológica de que o ser humano é um ser terreno ${ }^{11}$ e linguístico ${ }^{12}$ foi fundamental ao entendimento da integralidade da existência, superando-se, assim, uma concepção metafísica e essencialista da vida. ${ }^{13}$

A perspectiva metodológica delimitada possibilita a elaboração de uma série de questões, especificamente em função da superação do pensamento dissociativo que se inculturou nos últimos séculos. Algumas dessas perguntas são estas: O que é o ser humano?

\footnotetext{
${ }^{11}$ Em seu livro, A Condição Humana, Hannah Arendt, especificamente em seu Prólogo, insiste na condição terrena da qual não podemos abdicar. Em suas reflexões, não há possibilidade de imaginar-se uma vida humana fora ou para além da Terra (ARENDT, 2007).

${ }^{12}$ A vida humana, portanto, situa-se em duas casas (dois OIKOS): a terra e a linguagem, que não podem ser separadas ou dissociadas. A terra e a linguagem são dois constituintes e duas condições do humano. Veja sobre esta temática o artigo de CERVI, Jacson Roberto; HAHN, Noli Bernardo. A terra pede paz - a emergência do paradigma do cuidado e a superação do paradigma da conquista. In: Revista Internacional de Direito Ambiental, Caxias do Sul: Plenum, n. 15, p. 95-116, set/dez 2016.

${ }^{13} \mathrm{Na}$ América Latina há de se lembrar o imaginário cultural dos povos autóctones. A consciência integrativa da vida, consciência dos povos indígenas que habitavam e habitam em terras latino-americanas, há de ser resguardada e há de ser inculturada, em perspectiva emergente, para humanizar as relações entre os povos e para cultivar o cuidado com a casa comum, o planeta Terra.
} 
Noli Bernardo Hahn \& Rosângela Angelin: Como pensar o direito na atualidade? Diálogos interdisciplinares e transdisciplinares entre direito, cultura, religião e utopias nos movimentos sociais e culturais

O que é cultura? O que é Direito? O que é religião? O que significa afirmar que o ser humano é um ser cultural? Essas questões são importantes e, até, imprescindíveis, para que se inicie a pensar interligando saberes.

Na reflexão, a seguir, demarca-se e delimita-se uma perspectiva teórica desde a que se procura inter-relacionar Direito, cultura, religião e o tema da utopia a partir de movimentos sociais. A demarcação primeira está em compreender que o ser humano é um ser de linguagem. Nesta condição como ser linguístico abre-se a possibilidade de entender que cultura, Direito e religião são criações humanas, construídas em e a partir de linguagens paradoxais, dialéticas e complexas que, ao mesmo tempo, criam o humano. A questão central do estudo envolve o questionamento: Como inter-relacionar Direito, cultura, religião e movimentos sociais a partir de uma visão paradoxal, dialética e complexa da vida que possibilite noções de justiça que combatam violências, inferiorizações e discriminações e, ao mesmo tempo, motivem vivências e experiências de utopias que fortaleçam relações humanas de superação de uma cultura de injustiças?

Diversos caminhos poderiam ser seguidos para responder esta pergunta complexa. Porém, neste artigo, parte-se da compreensão de que cultura fundamentalmente é linguagem, religião é um integrante dessa cultura e todo Direito inventado pelos humanos, ao longo de sua história, é uma forma de linguagem que, por sua vez, como também a religião, é resultado cultural e, ao mesmo tempo, construtoras de culturas. O horizonte da integração de movimentos sociais está no sentido de ler e compreender que as utopias e os sonhos transgressores de uma cultura de injustiças, neles alimentados, alicerçam-se num entendimento paradoxal, complexo e dialético da vida, propiciado pela compreensão das linguagens criadas e criadoras do humano.

Para argumentar a resposta à questão central, o artigo encontra-se subdividido em quatro partes. Inicia-se com uma reflexão sobre a importância de o ser humano compreender-se como ser histórico; num segundo momento, procura-se refletir a dimensão do ser humano como ser cultural; na terceira seção do artigo, reflete-se sobre a dimensão 
Noli Bernardo Hahn \& Rosângela Angelin: Como pensar o direito na atualidade? Diálogos interdisciplinares e transdisciplinares entre direito, cultura, religião e utopias nos movimentos sociais e culturais

religiosa do humano, interligando-a com as dimensões ética e jurídica e, finalmente, na quarta parte da pesquisa, leem-se os sonhos alimentados em movimentos sociais como utopias vivenciais concebidas a partir de uma compreensão dialética, paradoxal e complexa da vida, mostrando que quem sonha com uma sociedade justa e sem discriminações e violências, combate todos os tipos de fundamentalismos e semeia horizontes à democracia. Nesta compreensão, dialoga-se com o sociólogo francês Alain Touraine, especificamente em relação ao entendimento da categoria ator/atriz social. Em síntese, procura-se apontar, neste artigo, uma conexão, que pode ser denominada metodológica, entre ética, lei, cultura, religião e movimentos sociais, salvaguardando sempre o entendimento da dinâmica paradoxal, dialética e complexa da linguagem.

\section{SER HUMANO COMO SER HISTÓRICO}

Ao longo da história de pesquisas e estudos sobre o ser humano, muito se tem escrito e a muitas conclusões se tem chegado. Nesta breve reflexão, procura-se relembrar e acentuar a perspectiva da historicidade do ser humano. Enfatizar que o ser humano é um ser histórico consiste em afirmar que a noção de tempo é essencial para o humano ser humano e se reconhecer humano. Ao recorrer ao termo essencial não se quer entender algum integrante do humano como essência metafísica, mas situar o tempo como fundamental para o humano manter sua identidade enquanto existência humana. A noção de tempo faz entender o humano como passado, presente e futuro integrados na identidade humana, tanto do ponto de vista individual, quanto coletivo. A reflexão ontológica de Martin Heidegger (2016) ajuda neste entendimento. O Ser não foi, não é e não será. O Ser está sendo. O Ser é evento, é acontecimento. O Ser acontecendo. A noção de tempo histórico e tempo existencial necessita ser adequada ao gerúndio. Esta linguagem não esfacela o tempo e nem a existência e faz entender o ser humano como um ser temporal que está sendo, que está acontecendo. A noção de ser histórico propicia a noção temporal, desde a ontologia, 
Noli Bernardo Hahn \& Rosângela Angelin: Como pensar o direito na atualidade? Diálogos interdisciplinares e transdisciplinares entre direito, cultura, religião e utopias nos movimentos sociais e culturais

como quem está sendo. Esta compreensão faz entender a vida humana histórica numa dinamicidade existencial sempre aberta e de possibilidade mutante (HEIDEGGER, 2016).

A noção de tempo, para reconhecer-se humano, perpassa por dimensões psicobiológicas. Sabe-se que a genética humana carrega uma história de longos períodos. A psique humana, da mesma forma, possui uma história milenar. Não se quer, nesta reflexão, aprofundar nem uma e nem outra dimensão. Apenas procura-se introduzir uma categoria que ajuda a entender o que se compreende por dimensão histórica do humano, tanto na perspectiva coletiva, quanto individual. A categoria de compreensão que se delimita e se integra é esta: memória linguística histórica.

Por memória linguística histórica enfatiza-se a história milenar que o sujeito humano está sendo, enquanto criador e resultado de linguagens que se ressignificam e se reinventam ao longo da história humana, produzindo significados e sentidos numa dinâmica de vida sempre em movimento, sendo este movimento não cíclico ${ }^{14}$, nem evolutivo ${ }^{15}$, mas apenas

\footnotetext{
14 Filósofos gregos, conhecidos como filósofos da natureza, Tales de Mileto, Anaximandro de Mileto, Anaxímenes de Mileto, Xenófanes de Cólofon, Pitágoras de Samos, observavam a natureza e predominantemente viam que ocorriam repetições cíclicas. A lógica natural lhes parecia cíclica e, de certa forma, sob esta lógica viam a vida humana. A percepção cíclica da vida foi gradativamente questionada com o desenvolvimento da tese de que a vida humana foge da lógica natural exatamente por sermos seres linguísticos e seres culturais. Sobre uma síntese da Filosofia grega, indica-se o livro de STOERIG, Hans Joachim. História geral da Filosofia. Petrópolis: Vozes, 2008, p. 95-116. Um breve, no entanto uma relevante e pertinente pesquisa publicada para entender a passagem de um entendimento naturalístico para uma compreensão cultural da vida humana encontra-se em LARAIA, Roque de Barros. Cultura: um conceito antropológico. 18. ed., Rio de Janeiro: Jorge Zahar Editor, 2005.

${ }^{15}$ Conceber a vida humana como evolutiva entrou em crise nas discussões antropológicas nos inícios do século XX. Edward Tylor (1832-1917), mesmo reconhecendo que cultura é tudo o que se aprende, ainda argumentava a lógica natural da evolução das culturas. Franz Boas e Alfred Kroeber foram os grandes críticos a Edward Tylor, contra argumentando a concepção naturalística da evolução das culturas. Veja uma síntese desse debate em LARAIA, 2005, p. 28s.
} 
Noli Bernardo Hahn \& Rosângela Angelin: Como pensar o direito na atualidade? Diálogos interdisciplinares e transdisciplinares entre direito, cultura, religião e utopias nos movimentos sociais e culturais

dinâmico ${ }^{16}$, ou seja, movido por um embate de forças múltiplas ${ }^{17}$, opostas ${ }^{18}$ e contraditórias $^{19}$.

Memória linguística histórica faz entender o ser humano como resultado de linguagens inerente a um pensamento que se apresenta complexo (forças múltiplas), dialético (forças opostas) e paradoxal (forças contraditórias). A complexidade, a dialeticidade e a paradoxalidade, por vezes, são processos dinâmicos vitais que sucedem no mundo da vida interligados, ininterruptos, interdependentes e ocorrendo ao mesmo tempo. A paradoxalidade, a dialeticidade e a complexidade não são processos ou formas de pensamento e ação que se opõem entre si, no sentido de um processo anular outro, mas se

\footnotetext{
${ }^{16}$ A noção de tempo herdada da cultura hebraico-judaica é muito interessante, comparando-a com a cultura majoritária grega. Para os hebreus e judeus não há repetição. Deus diz e faz todos os dias coisas diferentes e novas (BÍBLIA, Gênesis, 1). A concepção de tempo, sob esta perspectiva, é histórica e não cíclica.

${ }^{17}$ Entender a história humana como uma dinamicidade de forças múltiplas tem como pressuposto a teoria da complexidade de Edgar Morin. Na teoria da complexidade, todo e qualquer resultado é produto de uma multiplicidade de causas interligadas e interdependentes. Nesse horizonte, não se concebe e não se entende um efeito ou um resultado a partir de uma causa, como o pensamento moderno linear nos ensina (MORIN, 1996; 1999; 2001; 2009). Ao longo do presente artigo, concebe-se o Direito, as religiões, a cultura e os sonhos já vividos e ainda não completamente como resultados intermináveis de múltiplas forças que se conectam, interagem e interdependem.

${ }^{18}$ A história humana, como tudo o que o ser humano criou ao longo dos tempos, não se concebe apenas como resultado de múltiplas forças. Há de se acentuar que, inerente a essas múltiplas forças, há também um movimento de forças opostas. Daí a dialeticidade muito bem explicitada por Hegel e Marx. Hegel concebe esta dinamicidade no mundo das ideias. Marx, na dinamicidade da história, concebendo a luta de classes como motor da história. Indica-se, novamente, a obra de STOERIG, Hans Joachim. História geral da Filosofia. Petrópolis: Vozes, 2008, p. 395-434. Na reflexão que se faz no presente artigo, o Direito, as religiões, os sonhos e a cultura são, também, compreendidos como uma construção sempre inacabada de forças que se opõem. 0 texto explicita também esta perspectiva.

${ }^{19}$ A paradoxalidade é igualmente um caminho a ser observado para compreender a lógica da construção, da elaboração e da invenção das culturas, dos direitos, das utopias e das religiões que os seres humanos inventam. Conceber a lógica da vida e tudo o que o ser humano cria nessa sua vida a partir da dinamicidade de contrários que se inter-relacionam e se repelem, ao mesmo tempo, é um horizonte esclarecedor para entender muitos elementos que compõem a dinâmica da vida. A filosofia pós-moderna, desconstrucionista, como a de Jacques Derrida $(2002 ; 2005 ; 2006)$, ajuda a entender a paradoxalidade na criação de sentidos que emergem de espaços sociais e políticos e são fundamentais para a emergência do Direito e das religiões numa sociedade complexa e multicultural. Destaca-se, aqui, um artigo pertinente a este tema: HAHN, Noli Bernardo. Jackes Derrida: este que pensou desconstruções. In: OLIVEIRA JÚNIOR, José Alcebíades (org.). Faces do multiculturalismo: teoria, política, direito. Santo Ângelo: Ediuri, 2007, p. 185-197.
} 
Noli Bernardo Hahn \& Rosângela Angelin: Como pensar o direito na atualidade? Diálogos interdisciplinares e transdisciplinares entre direito, cultura, religião e utopias nos movimentos sociais e culturais

comunicam e, por vezes, uma das dinâmicas se sobrepõe, fazendo com que as demais permaneçam mais ocultas e menos intensas.

Linguagens, neste artigo, não representam somente falas ou códigos abstratos de comunicação. Linguagens integram, também, formas de ser, de se entender, de agir, de se inter-relacionar, de se comportar, de se vestir, de inventar e se inventar, de fazer, de interditar, de permitir, de proibir, de legislar, de rezar. Todo ato humano é linguagem, independente se este se evidencia de forma mais concreta ou mais abstrata.

Direito, utopias, cultura e religião, nesta reflexão, são compreendidos como sendo linguagem. As linguagens jurídica, cultural e religiosa, de certa forma, integram sonhos. Estas linguagens emergem da paradoxalidade de sentidos múltiplos e contraditórios, da dialeticidade social em que a vida acontece, ou seja, no meio de tensões e forças que se opõem e nascem, e também se originam da multiplicidade de razões ou causas que se entrelaçam e se cruzam. Religião, cultura e Direito, enquanto linguagens, provém de fontes múltiplas. Paradoxalidade (DERRIDA, 2005; HAHN, 2007), dialeticidade explicitada em Hegel e Marx (STOERIG, 2008, p. 395-434) e complexidade (MORIN,1999) são motores vitais da emergência de sonhos e utopias inerentes a culturas, religiões e direitos.

Essas três forças vitais mostram-se na história humana através de uma dinamicidade em que se interligam passado, presente e futuro, evidenciando que o ser humano é um ser histórico, produto de sentidos e vivências paradoxais, dialéticas e complexas e, ao mesmo tempo, criador desses sentidos e vivências ao se pensar direitos, utopias, culturas e religiões.

Concebendo o ser humano como produtor e, ao mesmo tempo, produto de linguagens, em tempos históricos, e entendendo o Direito, as culturas, os sonhos e as religiões como linguagens resultantes de múltiplas fontes, é imprescindível, integrar nesse 
Noli Bernardo Hahn \& Rosângela Angelin: Como pensar o direito na atualidade? Diálogos interdisciplinares e transdisciplinares entre direito, cultura, religião e utopias nos movimentos sociais e culturais

estudo o tema do ser humano como ser cultural. Esta é a temática, a seguir, apresentada e refletida.

\section{SER HUMANO COMO SER CULTURAL}

Para refletir e entender o ser humano como ser cultural, parte-se de uma definição de cultura de Humberto Maturana. ${ }^{20}$ Para Maturana "Uma cultura é uma rede de coordenações de emoções e ações na linguagem, que configura o modo particular de entrelaçamento do agir e do emocionar das pessoas que a vivenciam". Se cultura é entendida como uma rede de coordenações de emoções e ações na linguagem, conversar, afirma ele, é "este entrelaçamento do falar e do emocionar que acontece no viver humano dentro da linguagem". Esclarece ainda o autor, que "todo fazer humano ocorre na fala e que todas as atividades humanas se dão como sistemas distintos de conversação". Culturas, para Maturana, em síntese, são "redes de conversação" (MATURANA, 2007).

O ser humano, desde seu nascimento, é jogado dentro de uma "rede de conversação". Essa rede, em grande medida, cria e modela indivíduos e coletividades. Sob este viés, pode-se afirmar que o indivíduo é produto dessa "rede de conversação". No entanto, a "rede" não é estática e acabada. Esta se constitui numa dinâmica interminável de forças contraditórias, múltiplas e opostas. As forças, na verdade, são diálogos permanentes e sempre inacabados que constroem e reconstroem "redes". Nessa ótica, o ser humano não é apenas moldado por uma cultura, mas construtor e criador de culturas. Como o ser humano é, em parte, produto de uma cultura inacabada e sempre em construção, o próprio indivíduo também se encontra nessa situação. Ele é um ser inacabado em construção permanente. Da mesma forma, a "rede" que sujeita esse indivíduo e o molda, encontra-se num processo dinâmico de construção sem fim (MATURANA, 2007).

\footnotetext{
${ }^{20}$ Todas as citações de Humberto Maturana foram extraídas do Prefácio que este autor escreveu no livro de
} EISLER, Riane. Cálice e a Espada - nosso passado, nosso futuro. Rio de Janeiro: Imago editora, 2007. 
Noli Bernardo Hahn \& Rosângela Angelin: Como pensar o direito na atualidade? Diálogos interdisciplinares e transdisciplinares entre direito, cultura, religião e utopias nos movimentos sociais e culturais

Os múltiplos direitos, as religiões e as utopias despertados e alimentados pelos humanos são linguagens integrantes de uma rede, de uma cultura e são moldados por essa "rede de conversação", numa dinâmica de acabamento e inacabamento interminável. As raízes fundantes de sonhos, de direitos e de religiões permanecem e, ao mesmo tempo, fluem com o tempo ao receber novas interpretações numa dinâmica de conversações onde, ao mesmo tempo, sucede o permanente e o mutante.

Ao abordar o tema envolvendo a diversidade cultural, Maturana destaca que culturas distintas, enquanto modos diferentes de convivência humana "são redes diferentes de conversação". "E uma cultura se transforma em outra (cultura) quando muda a rede de conversações que a constitui e define". Portanto são redes de conversação que constituem e definem a cultura e, por conseguinte, também, os direitos, as noções de justiça, os sonhos e as religiões (MATURANA, 2007).

Nesta visão, direitos, utopias e religiões se constituem em formas de linguagem constituídas por diferentes conversas que se mesclam, se processam e se interceptam numa determinada região e contexto. Toda e qualquer cultura, pela dinamicidade de sua composição, é híbrida. Constituindo-se a partir de uma multiplicidade de razões, sejam estas sociais, geográficas ou de qualquer natureza, a cultura - como também as esperanças vividas e projetadas, o Direito e a religião - vem constituídos a partir de uma multiplicidade de conversações. Direitos e religiões, inerentes a processos culturais, se constituem hibridamente pelas forças vitais complexas, dialéticas e paradoxais presentes nas linguagens da historicidade humana, gerando permanentemente numa dinâmica geracional sonhos e utopias contextuais e, ao mesmo tempo, universais.

Toda identidade cultural, por razões históricas, geográficas, sociais e políticas, fundase num processo dinâmico plural pelo qual não se pode imaginar a construção de identidades oriundas, por exemplo, apenas de razão étnica. Direitos, utopias e religiões provém de 
Noli Bernardo Hahn \& Rosângela Angelin: Como pensar o direito na atualidade? Diálogos interdisciplinares e transdisciplinares entre direito, cultura, religião e utopias nos movimentos sociais e culturais

múltiplas conversações que se mesclam, se hibridizam, se interceptam e se difundem dentro de uma dinâmica em que as raízes permanecem, mas o tempo os modifica e os transforma. Não que o tempo seja um ente metafísico com vida própria. O tempo que aqui se menciona é o tempo dos homens e das mulheres, com seu passado, presente e futuro, interligados como um tempo que está sendo, na qualidade de gerúndio (HEIDEGGER, 2016). Estas pessoas, vivendo no tempo histórico assim concebido, encontram-se inseridas num contexto cultural e espacial, no qual vivem dialeticamente, paradoxalmente e complexamente, processando sentidos e significados para suas vidas. Ao processar significados e sentidos, os humanos inventam sonhos, direitos e religiões.

A noção ontológica heideggeriana de tempo nos desafia a pensar o Ser como está sendo e não no sentido estático (HEIDEGGER, 2016). Nesta perspectiva, integra-se, ora, a categoria de compreensão tradição, que ajuda a sustentar e a esclarecer a reflexão que se está fazendo. O que é tradição?

José Severino Croatto (1984), em sua obra Hermenêutica Bíblica, pergunta: o que é tradição? A resposta por ele concedida é muito simples, mas muito pertinente ao que aqui está se refletindo. Argumenta Croatto que tradição inicia com uma experiência significativa que alguém faz, e por ser muito significativa para ele, conta-a a outros; este alguém pode ser uma pessoa ou um grupo. Pode ser uma experiência subjetiva ou intersubjetiva. Os outros que escutam essa experiência significativa de alguém podem ser apenas ouvintes e não dar muita atenção ao que escutaram, ou podem integrar-se, envolver-se nessa experiência significativa e contar e recontar adiante a outros, como experiência também deles. Esse contar e recontar num processo dinâmico de amplificação passaria por vários níveis ou estágios: a experiência é vivida, contada, celebrada, memorizada, recontada numa dinâmica que os novos sujeitos que a ouvem e a celebram, integram-se nessa experiência fundante. Tradição, sob esse olhar é, portanto, uma experiência fundante significativa sempre revivida e ressignificada, e nesse processo de ressignificação e revivamento ocorre uma amplificação 
Noli Bernardo Hahn \& Rosângela Angelin: Como pensar o direito na atualidade? Diálogos interdisciplinares e transdisciplinares entre direito, cultura, religião e utopias nos movimentos sociais e culturais

de sujeitos que participam dessa ininterrupta memória sempre atualizada, revisitada e transformada.

Tradição, portanto, não é mera repetição. Tradição é memória. Memória consiste numa atualização da experiência significativa primeira, que nunca mais se repete, pois serão novos sujeitos que se encontram em conversações distintas, em linguagens diferentes, em culturas em construção num tempo histórico com suas forças paradoxais, dialéticas e complexas.

Relacionando Direito, utopia e religião com tradição, pode-se dizer que a linguagem religiosa, de esperança, assim como a linguagem jurídica, são tradições, são memórias sempre atualizadas de uma experiência que se tornou significativa a muitos num processo dinâmico histórico de revivamento de uma experiência fundante utópica, jurídica e/ou religiosa. Um direito, por exemplo, por mais que lembre e aponte para a origem, não é regido pelo princípio da imobilidade e da fixidez. Um direito pode simbolizar a experiência significativa primeira, mas esta experiência vai se mobilizando e se adaptando em novos espaços geográficos e humanos. Experiências utópicas, religiosas e jurídicas, em si, não se repetem. Estas são memorizadas, atualizadas com influências múltiplas em movimentos paradoxais, dialéticos e complexos, vividos em sociedade e em contextos culturais peculiares.

O ser humano como ser cultural é resultado de conversações múltiplas e, ao mesmo tempo, multiplicador de conversas que, por conseguinte, geram experiências utópicas, jurídicas e religiosas em novos contextos e por novas gerações, criando outras culturas numa dinamicidade em que experiências originárias são relidas, ressignificadas e revividas.

A reflexão feita até o presente momento possibilita enxergar o ser humano inventando o humano, a partir de forças vitais inerentes a sua linguagem, sendo o próprio ser humano criador e criatura de suas linguagens que se manifestam em contradições, 
Noli Bernardo Hahn \& Rosângela Angelin: Como pensar o direito na atualidade? Diálogos interdisciplinares e transdisciplinares entre direito, cultura, religião e utopias nos movimentos sociais e culturais

oposições e múltiplas inter-relações e interdependências. A reflexão segue nessa compreensão, enfatizando-se, ora, distintas dimensões do humano que as pessoas são, ao mesmo tempo. Esse "ao mesmo tempo" transmite um entendimento de superação do conhecimento dissociativo e alcança níveis da compreensão da integralidade da vida.

\section{SER HUMANO COMO SER RELIGIOSO, ÉTICO E JURÍDICO, AO MESMO TEMPO}

Para entender o ser humano como ser religioso, ético e jurídico, neste artigo, onde se compreende cultura como uma rede de conversações criadas e criadoras do humano, não se parte de uma concepção dualista de homem ou de mulher. O ser humano não é compreendido, nesta reflexão, como corpo e mente - ou como corpo e alma, ou matéria e não-matéria, ou res cogitans e res extensa - e, sim, como uma multiplicidade de dimensões integradas. ${ }^{21}$ A dimensão da crença é uma entre muitas das dimensões (cognição, emoção, psique, vontade, corporeidade, etc.) que identificam os seres humanos, numa visão integrada das múltiplas e diversas dimensões que constituem o humano. A crença, por exemplo, não se encontra desintegrada da corporeidade, da cognição, da emoção, da vontade, da psique, entre outras. Todas as dimensões que constituem integradamente o humano não são, em princípio, inatas. Estas são desenvolvidas ao longo do tempo histórico no qual as pessoas se tornam humanas, não de forma evolutiva, nem cíclica, mas inerente a uma dinâmica de vida que se apresenta como um jogo linguístico de contradições, oposições e de interfaces complexas.

\footnotetext{
${ }^{21}$ Toda a Filosofia existencialista pode ser entendida como uma crítica à compreensão dualista do ser humano. "Existo, logo penso" impõe-se como crítica ao entendimento do paradigma cartesiano "Penso, logo existo". Na Filosofia existencialista, a existência precede a essência. Um autor importante que pode ser pesquisado para o entendimento dessa temática é Maurice Merleau-Ponty (2016). Outra obra é a de GHIRALDELLI JUNIOR, Paulo. O corpo - Filosofia e educação. São Paulo: Ática, 2007.
} 
Noli Bernardo Hahn \& Rosângela Angelin: Como pensar o direito na atualidade? Diálogos interdisciplinares e transdisciplinares entre direito, cultura, religião e utopias nos movimentos sociais e culturais

Portanto, aprende-se em redes de conversações a crer, a acreditar, a confiar, a rezar, a ser religioso, a ser ético, a ter noção de deveres e direitos. Acreditar em si, confiar no outro humano e crer num ser divino, no grande Outro, é resultado de um processo de aprendizagem dentro de uma determinada cultura. Da mesma forma, a internalização de deveres e a noção de direitos são aprendizagens adquiridas dentro de um processo educacional que acontece na informalidade e na formalidade. Enquanto seres em construção, sempre inacabados e imperfeitos, os sujeitos criam linguagens sempre confiantes na maturação ou no desenvolvimento do humano inerente a um processo educativo de forças linguísticas vitais complexas, contraditórias e opostas.

O corpo também é compreendido como sendo um "complexo psico-linguístico" (ALVES, 2002), e não apenas como matéria (Soma, em grego, carne, corpo). Na concepção dualista, o corpo é apenas matéria. Enquanto "complexo psico-linguístico" a corporeidade é compreendida como sendo capaz de interligar realidade concreta e simbologia. O cérebro humano, pela sua capacidade memorial e simbólica, faz o ser humano compreender-se como ser simbólico que não apenas vive a realidade concreta, mas também a realidade simbólica. A vida humana, ao mesmo tempo, é concreta e simbólica. Porém, a concretude e a simbologia não são duais. Estas são realidades interdependentes, interligadas, mescladas, no entanto distintas.

As linguagens religiosa, ética e jurídica são fundamentalmente simbólicas. A linguagem religiosa faz viver a esperança em meio ao caos. A palavra teológico-religiosa revive a vida em meio à morte. As pessoas, em meio a tragédias e mortes, entoam cantos de louvor, de gratidão e de esperança! O discurso teológico-religioso ativa o sonho, a utopia, a 'passagem' do concreto ao simbólico, o eskaton ${ }^{22}$, mesmo que a experiência real não combine com sonhos e utopias. Se no cotidiano as pessoas ingerem vitaminas, proteínas e sais minerais, imprescindíveis à dimensão somático-corporal, também ingerem, pela

\footnotetext{
22 Palavra grega que tem a ver com a finalidade última da existência humana. Neste artigo, a dimensão teleológica e a dimensão escatológica convergem para o sonho, a utopia, tema pertinente ao conteúdo central da reflexão que se faz nesse texto.
} 
Noli Bernardo Hahn \& Rosângela Angelin: Como pensar o direito na atualidade? Diálogos interdisciplinares e transdisciplinares entre direito, cultura, religião e utopias nos movimentos sociais e culturais

dimensão da crença, símbolos, significados, sentidos, memórias, ditos, interditos, proibições, benditos e malditos. Bênçãos e maldições são ditos, são palavras. Interdições são palavras. Proibições são linguagens. Ingerem-se, portanto, palavras. No entanto, estas palavras, dentro da lógica de uma rede de conversação, denotam sentidos e significados.

Nas tradições religiosas, o sentido religioso e o sentido jurídico se conectam em dois níveis. Ambas as linguagens inserem o humano no simbólico e no nível ético. Benditos, malditos, interditos, permissões e proibições identificam linguagens que denotam, ao mesmo tempo, sentido jurídico, ético e religioso. No momento em que uma divindade interdita uma ação, isso acontece porque a sociedade ou uma determinada cultura não permite que tal se suceda, e se espera, também, que esta interdição seja internalizada pelos indivíduos, como uma voz interior (uma lei ético-moral, Autós - Nomos - Minha própria Lei - Autonomia).

As linguagens religiosas, portanto, como linguagens culturais, criadas em contextos diversos, ao longo da história, denotam sentidos ético e jurídico. A lei jurídica, tal como é compreendida a partir da tradição republicana, provém do Estado, no entanto fala-se em vontade do Estado. Esta vontade emerge e se fortalece a partir de forças complexas, contraditórias e opostas vividas pelas individualidades e coletividades. Vontade representa um conceito aglutinador de sentido jurídico, religioso e ético. Como a linguagem teológicoreligiosa é linguagem cultural, criada por homens e mulheres em determinados contextos, a vontade divina representa a vontade, o sonho, a utopia, a esperança, a desesperança, bem como a luta dos que criaram, naquele contexto, tal linguagem. A lei divina quando internalizada pelas pessoas, torna-se ética e moral. Porém, a lei reconhecida divina, enquanto linguagem, é sonho de grupos articulados. Assim, a vontade do Estado Republicano é resultado de embates contraditórios, opostos e complexos por entidades e organizações que se articulam no presente, com raízes no passado, e que projetam interesses, sonhos e utopias. A lei, sob este olhar, é simbólica, ética e religiosa. 
Noli Bernardo Hahn \& Rosângela Angelin: Como pensar o direito na atualidade? Diálogos interdisciplinares e transdisciplinares entre direito, cultura, religião e utopias nos movimentos sociais e culturais

A lei, como linguagem simbólica, proveniente da vontade do Estado, uma vontade articulada a partir de embates, debates, oposições e contradições de coletividades organizadas, procura representar sonhos e esperanças, por vezes longe da realidade existencial de indivíduos e povos. Os direitos humanos são um exemplo do que se está afirmando. A linguagem simbólica integra a força vivencial do "já e ainda não" 23 , ou seja, os direitos humanos "já" estão sendo vividos e, ao mesmo tempo, "ainda não". Os direitos humanos, no entanto, não representam apenas a vontade de um ente chamado Estado, mas também representam o anseio de milhares de indivíduos que procuram internalizar os valores que esses direitos integram. Este anseio ou esta vontade faz com que a lei se torne ética, ou seja, uma luz ou um horizonte comportamental de pessoas. A lei e a ética, ao integrar em sua linguagem a realidade e o sonho, a concretude e a simbologia, compõem em seu discurso o que há de mais central na linguagem religiosa: a u-topia estendendo-se do Topos $^{24}$; o não-lugar estendendo-se do lugar; a não-realidade estendendo-se da realidade a ser superada. A relação entre não-realidade (simbologia) e realidade a ser superada é umbilical. Não há desconexão. Os movimentos vitais da contradição, da complexidade e da oposição existentes nas relações humanas, como na vida em geral, propiciam o afastamento entre a realidade vivida e a realidade sonhada sem dissociar, esfacelar ou desagregar.

O ser humano, ao mesmo tempo, é um ser religioso, ético e jurídico, por ser um ser que interliga, através da linguagem, realidades vividas e realidades a serem vividas. O discurso religioso, jurídico e ético representam vontades individuais e coletivas, ao mesmo tempo. Esta vontade não é um ente metafísico, imóvel, imutável, onisciente e onipotente. Vontade não possui vida em si. Esta vontade é resultado cultural de forças contraditórias, complexas e opostas existentes num tempo e espaço históricos, sempre em construção num movimento ininterrupto das gerações humanas.

\footnotetext{
${ }^{23}$ Essa expressão vem da visão escatológica e cristológica das reflexões teológicas da Teologia da Libertação, na América Latina, realizadas especialmente a partir dos anos setenta do século XX. "Já e ainda não" refere-se nesse horizonte teológico à ideia do Reino Já, mas ainda não completamente. (SOBRINO, Jon, 1983). Em nosso texto, a referência a essa compreensão e o uso que dela se faz converge em sentido a este significado. $\mathrm{O}$ sonho e a utopia, em parte, já são vivenciados pelos atores e atrizes sociais, no entanto a luta é movida por esperanças, conquistas e concretizações para gerações futuras.

${ }^{24}$ Em grego, Topos significa lugar.
} 
Noli Bernardo Hahn \& Rosângela Angelin: Como pensar o direito na atualidade? Diálogos interdisciplinares e transdisciplinares entre direito, cultura, religião e utopias nos movimentos sociais e culturais

A seguir, mesclam-se, em parte, reflexões já iniciadas anteriormente, com o tema das utopias e sonhos em Movimentos Sociais e Culturais. A reflexão que segue, tem por objetivo central evidenciar o quanto são relevantes os Movimentos Sociais e Culturais para se construir sociedades democráticas que integrem noções de justiça que impeçam violências, discriminações e as múltiplas formas de injustiças.

\section{UTOPIAS E SONHOS NOS MOVIMENTOS SOCIAIS E CULTURAIS: CONTRIBUIÇÕES PARA A DEMOCRACIA}

O ser humano, pela sua condição linguística e de possibilidade simbólica, projeta sua vida para além da concretude das coisas materiais. Talvez seja esta uma das dimensões do humano que o torna ser humano ao longo da história, no horizonte ontológico do Ser sendo (HEIDEGGER, 2016). Os sujeitos históricos não vivem agarrados à concretude das realidades, mas ultrapassam, transcendem, abstraem. Criam mundos. Inventam sentidos e significados. Interpretam. Mudam. Transformam. Reinventam. Ressignificam. Afinal, não são seres reduzidos à lógica biológico-natural, mas são seres humanos que, além de integrar a vida das leis e dos elementos naturais, também são seres sócio-históricos-culturais que, pela linguagem, inventam humanidades. Por conseguinte, pode-se afirmar que, pela possibilidade de inventar simbolicamente mundos e linguagens, os seres humanos podem, também, se desumanizar. A paradoxalidade inerente às linguagens, em que os sentidos e significados emergem de contextos, é condição de possibilidade de caminhos contraditórios. Da mesma forma, no mundo simbólico criado por humanos, a condição de opor-se a sentidos e significados distintos é sempre, ao mesmo tempo, condição de possibilidade de humanização, como de desumanização. Quando há o enfrentamento de diferenças, a oposição abre o caminho do diálogo, como, também, do fechamento de posições. No momento em que sucede a segunda possibilidade, a do fechamento, o fundamentalismo 
Noli Bernardo Hahn \& Rosângela Angelin: Como pensar o direito na atualidade? Diálogos interdisciplinares e transdisciplinares entre direito, cultura, religião e utopias nos movimentos sociais e culturais

vence a batalha e se instaura o que se conhece como "objetividade da cultura" (MO SUNG; SILVA, p. 30), da qual decorrem discriminações, violências e inferiorizações. ${ }^{25}$ Quando esta se instaura, fecham-se os caminhos ao reconhecimento da alteridade e, também, impede-se o nascimento do que, neste artigo, se entende por utopia ou sonho.

O que se concebe como utopia e ou sonho emerge de condições de possibilidades do enfrentamento de oposições, da existência de contradições e de múltiplas inter-relações interdependentes. Utopias e sonhos não estão pré-dados na razão individual ou no imaginário de indivíduos isolados. O nascedouro de utopias, que são linguagens convertidas em crenças que transcendem a realidade que se crê superar, é o espaço que se cria entre humanos em condições de diálogo, de enfrentamentos, de constante ressignificação de sentidos a partir de contextos e de criação e recriação de significados a partir do reconhecimento de uma pluralidade infinita de significantes inter-relacionados. Numa linguagem convergente à lógica argumentada em todo o artigo, afirma-se que utopias e sonhos emergem em meio a oposições, a contradições e, por meio de infinitas inter-relações e interdependências.

Cabe, nessa compreensão, integrar o entendimento de Alain Touraine sobre o tema ator e ou atriz social. Para este autor, atrizes e atores sociais nascem em meio à resistência e à criação. Resistir e criar são duas ações centrais para a emergência de atrizes e de atores sociais. Resistir contra uma estrutura mercadológica e contra comunitarismos fundamentalistas é imprescindível para autoconstruir-se ator/atriz (TOURAINE, 2004, p. 34; 2007, p. 41).

\footnotetext{
${ }^{25}$ Veja como os autores citados sobre "objetividade da cultura" entendem-na: "A objetividade da cultura tem um segundo aspecto. É o seu poder coercitivo. A coerção fundamental é a percepção desta cultura como "a" realidade. Isto é, os que não compartilham com as normas, os valores e os significados estabelecidos por esta cultura são considerados como anormais pela sociedade. Aquele que se "desvia" da normalidade da cultura estabelecida sofre não somente a sanção subjetiva da "culpa moral", mas também a possibilidade do terror da loucura." (MO SUNG, Jung; SILVA, Josué Cândido da. Conversando sobre ética e sociedade, 2001, p. 30).
} 
Noli Bernardo Hahn \& Rosângela Angelin: Como pensar o direito na atualidade? Diálogos interdisciplinares e transdisciplinares entre direito, cultura, religião e utopias nos movimentos sociais e culturais

Na compreensão de Alain Touraine, o sujeito habita o indivíduo. Constitui-se como desejo de se tornar ator e atriz. Este desejo de encontra-se no indivíduo. Mora dentro dele como força, como coragem, como poder de. Para Touraine, sujeito é compreendido como este poder de, este desejo de, esta força para, no entanto sem conteúdo social (TOURAINE, 2004, p.34-35). A estrutura ou sistema de mercado e os comunitarismos fundamentalistas abafam e anulam o sujeito, que é este poder de, nos indivíduos. O mercado e as comunidades fechadas impedem que o indivíduo se torne ator e atriz social, em processos de subjetivação e de autonomização, por exatamente anular a força emergente de criação nesse indivíduo, que Touraine denomina sujeito. ${ }^{26}$ Trazendo a palavra do autor referido sobre o tema em discussão, assim ele escreve:

Quero dizer com isso que o concebo, inicialmente e antes de tudo, como luta de sobrevivência em face da enorme pressão da economia, do consumo, da cultura de massa e também do comunitarismo. Para mim, o sujeito é o olhar sobre o corpo individual, não-social, apenas vivo e sexuado. (2004, p. 34)

Em outro livro, ao tratar do mesmo assunto, afirma:

Já não sabemos quem somos. A nossa patologia principal teve sua origem por longo tempo no peso repressivo que as proibições, as leis exerciam sobre nós; vivemos uma patologia às avessas, a da impossível formação de um eu, afogado na cultura de massa ou encerrado em comunidades autoritárias. (1998, p. 71)

A integração da teoria de Alain Touraine sobre atores e atrizes sociais ajuda e nos desafia a pensar sonhos e utopias em movimentos sociais não fugindo da lógica reflexiva que se faz em todo o artigo. A força criacional inerente e emergente do indivíduo para se tornar ator ou atriz se evidencia na resistência. Na compreensão do autor francês, somente consegue resistir quem possui o domínio de si construído em profundos processos de subjetivação, de individuação e de autonomização. No entanto, a categoria ator social ou atriz social não identifica o indivíduo-sujeito enclausurado sobre si e fechado sobre seu

\footnotetext{
${ }^{26}$ Para o tema em discussão, um artigo pertinente a esta reflexão é HAHN, Noli Bernardo. A afirmação do sujeito (de direitos) num processo de resistência: A emergência do sujeito humano como liberdade e como criação. In: FALCÃO, Clóvis Marinho de Barros; CESAR, Constança Terezinha Marcondes. Filosofia do Direito. Florianópolis: XXIV Encontro Nacional do CONPEDI - UFS, 2015, p. 4-18.
} 
Noli Bernardo Hahn \& Rosângela Angelin: Como pensar o direito na atualidade? Diálogos interdisciplinares e transdisciplinares entre direito, cultura, religião e utopias nos movimentos sociais e culturais

mundo individualizado. Touraine faz uma crítica relevante, do ponto de vista psicológicosocial, e pertinente à lógica de sua teoria, ao narcisismo. O narcisista é exatamente o antônimo da atriz ou do ator social. O narcisista apenas enxerga e admira a si. O ator e a atriz, por serem autônomos, veem-se a si, não abdicam de si, no entanto enxergam os outros e se importam com os outros. Nessa ótica, entende-se Touraine quando afirma que "para mim, as palavras sujeito, movimento social e democracia são inseparáveis umas das outras" (2004, p. 53).

A luta contra o narcisismo e contra o afogamento ou anulação do sujeito em comunitarismos fundamentalistas se processa, fundamentalmente, na resistência contra os poderes que se instalam na sociedade. Para conseguir resistir, os processos de subjetivação são imprescindíveis. É neste sentido que se deve entender a seguinte ideia: "A subjetivação é a penetração do Sujeito no indivíduo e, portanto, transformação - parcial - do indivíduo em Sujeito" (2002, p. 222). Para Alain Touraine,

A subjetivação é o contrário da submissão do indivíduo a valores transcendentes: o homem se projetava em Deus; doravante, no mundo moderno, é ele que se torna o fundamento dos valores, já que o princípio central da moralidade se torna liberdade, uma criatividade que é seu próprio fim e se opõe a todas as formas de dependência. (2002, p. 223)

Relevante destacar que a consciência de se importar com o outro e ser afetado por ele é adquirida em processos educacionais e pedagógicos, ao mesmo tempo, de subjetivação e socialização. Não se pode esquecer que Touraine é liberal. Sua ênfase, ao se falar em educação, está em se educar e ser educado em processos de subjetivação mais do que em processos de socialização $(2004$, p. 31). Porém, os atores e atrizes emergem e apontam em relações sociais. Daí a importância dos movimentos sociais e culturais na visão do sociólogo francês.

Muitos movimentos sociais, ao longo da história, também podem ser compreendidos, na visão de Touraine, como movimentos culturais. A diferença e a relação 
Noli Bernardo Hahn \& Rosângela Angelin: Como pensar o direito na atualidade? Diálogos interdisciplinares e transdisciplinares entre direito, cultura, religião e utopias nos movimentos sociais e culturais

entendem-se nesse aspecto: a dimensão teleológica dos movimentos sociais está na transformação de estruturas sociais, sem necessariamente transformar o sujeito humano envolvido nessa transformação. Os movimentos culturais, ao contrário, além de mover estruturas, modificam e transformam pessoas. Nos processos de subjetivação, individuação e autonomização sucede a internalização de outros valores, de outras formas possíveis de articular e viver a vida, de romper com valores desumanos que podem provir da tradição.

Sonhos e utopias, neste artigo, concebem-se nessa capacidade de criação de outras estruturas e de outros sujeitos humanos que se modificam e se reestruturam em processos intermináveis de autonomização, ressignificando sentidos e significados em que a dimensão teleológica aponte para categorias como emancipação, libertação, democracia, cidadania e vivências onde não haja espaço para discriminações, inferiorizações e violências.

Movimentos sociais e culturais são, portanto, encontros de linguagens convergentes que se articulam a partir de atores e atrizes sociais que comungam dimensões teleológicas em que se resiste a realidades avaliadas como injustas e se transgridem valores concebidos como não emancipadores, não libertadores, não democráticos, não cidadãos e geradores de preconceitos que incidam e fomentem vivências violentas e discriminadoras. Sonhos e utopias são, portanto, dimensões teleológicas "já e ainda não"27, vivenciadas em movimentos sociais e culturais e que brotam em meio a redes de conversações movidas em processos linguísticos dialéticos, paradoxais e complexos. O sonho, por conseguinte, é movido e gerado, por atores e atrizes sociais que se criam resistindo contra forças anuladoras do sujeito que nos habita, em processos intermináveis de subjetivação conjugados com os de socialização. Os movimentos sociais e, ao mesmo tempo, culturais são uma escola de aprendizagem e de construção de sujeitos cidadãos livres, democráticos e emancipados a

\footnotetext{
27 Retomando a explicação já dada anteriormente, essa expressão vem da visão escatológica e cristológica das reflexões teológicas da Teologia da Libertação, na América Latina, realizadas especialmente a partir dos anos setenta do século XX. "Já e ainda não" refere-se nesse horizonte teológico à ideia do Reino Já, mas ainda não completamente. (SOBRINO, Jon, 1983). Em nosso texto, a referência a essa compreensão e o uso que dela se faz converge em sentido a este significado. O sonho e a utopia, em parte, já são vivenciados pelos atores e atrizes sociais, no entanto a luta é movida por esperanças, conquistas e concretizações para gerações futuras.
} 
Noli Bernardo Hahn \& Rosângela Angelin: Como pensar o direito na atualidade? Diálogos interdisciplinares e transdisciplinares entre direito, cultura, religião e utopias nos movimentos sociais e culturais

partir de uma visão não narcísica, mas de uma concepção de vida em que o outro se torna um integrante para o desabrochar do sentido da vida. O sonho e a utopia, neste horizonte, conectam-se com alteridade, democracia, emancipação, liberdade e com o reconhecimento da diversidade. A dialeticidade, a paradoxalidade e a complexidade, quando internalizadas no convívio humano, evidenciam-se fundamentais para não somente conceber e viver a tolerância, mas a acolhida da diferença e da alteridade em sociedades democráticas. Eis um dos sonhos e uma das utopias dos movimentos sociais e culturais ao longo da história, no entanto, sabe-se da necessidade da vigilância permanente para que as linguagens, enquanto fontes de noções de justiça, não sejam convertidas em fontes de noções de injustiça. A vigilância permanente é necessária exatamente pelas dimensões paradoxal, dialética e complexa inerentes à linguagem produzida pelos humanos e que, ao mesmo tempo, podem produzir o humano e o desumano.

\section{CONCLUSÃO}

A questão central delimitada no início deste artigo envolveu o questionamento: Como inter-relacionar Direito, cultura, religião e movimentos sociais a partir de uma visão paradoxal, dialética e complexa da vida e que possibilite noções de justiça que combatam violências, inferiorizações e discriminações e, ao mesmo tempo, motivem vivências e experiências de utopias que fortaleçam relações humanas de superação de uma cultura de injustiças? Pode-se, nessa conclusão, acrescentar a esta pergunta um contexto a que toda a reflexão feita, de certa forma, teve como pressuposto: Como pensar o Direito para uma sociedade complexa e multicultural?

Partiu-se de uma crítica a um paradigma moderno que dissocia, separa e fragmenta para se chegar a conhecimentos. Nesse estudo, propôs-se um entendimento da vida humana a partir da coexistência de três forças vitais que se mesclam e interdependem num movimento histórico ininterrupto ao longo das gerações humanas. Estas forças não são entes 
Noli Bernardo Hahn \& Rosângela Angelin: Como pensar o direito na atualidade? Diálogos interdisciplinares e transdisciplinares entre direito, cultura, religião e utopias nos movimentos sociais e culturais

metafísicos, possuindo vida em si, porém, coexistem na linguagem dinâmica das relações humanas terrenas que se mostram complexas, contraditórias e opostas.

Conceber o ser humano como linguagem significa compreender que ele se move em linguagens contraditórias, opostas e complexas, gerando-se no encontro dessas linguagens e, ao mesmo tempo, gerando as mais distintas culturas. Esse entendimento é fundamental para se conceber uma justiça sem violências, discriminações e inferiorizações. A noção democrática e as noções de tolerância e acolhida concebem-se a partir do reconhecimento de que pelas linguagens possibilita-se a criação de inúmeras formas e jeitos de viver o humano. Os fundamentalismos concebidos e estabelecidos ao longo da história humana negavam a pluralidade e a diversidade humanas, oriundas da condição terrena e linguística da humanidade. A mentalidade fundamentalista nega a dialeticidade, a paradoxalidade e a complexidade inerentes à linguagem humana e geram, por essa razão, discriminações, inferiorizações e violências. ${ }^{28}$

O Direito, as religiões, as utopias e as culturas, enquanto linguagens produzidas pelos humanos ao longo da história podem conectar-se de diversas formas. Este artigo apontou para uma conexão, que pode ser chamada de conexão metodológica. O Direito possui como uma das suas finalidades centrais a Justiça. Justiça pode representar o "já e ainda não". Os horizontes teleológico e escatológico ${ }^{29}$ encontram-se inerentes à luta por um direito que aponta e almeja justiça. Esses horizontes, da mesma forma, encontram-se integrados na linguagem religiosa. A realidade concreta deverá ser superada por uma realidade que se almeja e se sonha. Neste viés, deveres, direitos, interditos, proibições, permissões, malditos, benditos são linguagens construídas juridicamente e teologicamente, a partir de relações complexas, contraditórias e opostas em que o horizonte do desejado (do "ainda não", o

\footnotetext{
${ }^{28} \mathrm{Na}$ América Latina, tivemos muitas experiências em que a mentalidade fundamentalista e de totalidade foi vivenciada. A exclusão, o não reconhecimento, a anulação, a morte são conceitos e categorias de compreensão de fácil apreensão e compreensão para quem viveu e vive em terras latino-americanas. De outra ótica, porém, enquanto emergência da resistência, a inclusão, o reconhecimento, a integração, o acolhimento, o cuidado, representam sinais de vida vividos em movimentos emancipatórios e de libertação.

${ }^{29}$ No artigo há uma semelhança entre Telos e Eskaton. O sentido teleológico e o sentido escatológico apontam para a finalidade última, como horizonte a ser almejado e conquistado. A Justiça aponta-se, aqui, como um horizonte que nunca será plenamente alcançado, mas situa um caminho e uma finalidade do sentido humano.
} 
Noli Bernardo Hahn \& Rosângela Angelin: Como pensar o direito na atualidade? Diálogos interdisciplinares e transdisciplinares entre direito, cultura, religião e utopias nos movimentos sociais e culturais

escatológico), encontra-se umbilicalmente integrado com a existência real que se deseja superar, transformar e/ou recriar.

A criação, a recriação, a transformação, a mudança se processa na e pela linguagem. A vida humana acontece na tensão e na conexão do real vivido e do real sonhado. É função do direito, objetivo primordial dos movimentos sociais e culturais e missão das igrejas assegurar a vida nessa tensão, pois o sonho, a utopia, a esperança e a justiça jamais deverão ser desintegrados das linguagens que fazem emergir as distintas culturas. Os movimentos sociais e culturais, em especial, integram em sua concepção e ação a vigilância crítica do discernimento da ênfase linguística para que se articulem entendimentos culturais de combate a todas as possíveis injustiças, que se possam gerar na convivência das relações humanas.

Como pensar o Direito na atualidade? Esta pergunta, em grande medida, foi respondida ao longo do texto. Enfatiza-se, no entanto, a ideia de que a consciência da integralidade da vida impossibilita pensar o Direito desvinculado de uma concepção interdisciplinar e transdisciplinar. A racionalidade dissociativa e instrumental não possibilita reflexões que concebam a linguagem, uma das casas do humano, como uma casa em que habitam, numa interdependência vital, dialeticidades, complexidades e paradoxalidades. Pensar o Direito, na atualidade, exige um raciocínio metodológico que, de fato, integre um pensamento paradoxal, dialético e complexo para criar-se noções de justiça que correspondam aos desafios de uma sociedade multicultural e complexa, onde diferenças e diversidades necessitam ser reconhecidas juridicamente e socialmente. ${ }^{30}$ Esta, sem dúvida, é uma das grandes utopias dos movimentos sociais e culturais.

\footnotetext{
${ }^{30} \mathrm{Ali}$, expressa-se um sonho latino-americano que emerge dos movimentos sociais populares. A diversidade cultural deve ser preservada, democratizada e reconhecida. Juridicamente, a diversidade necessita ser protegida. As Constituições de nossos países, por um imperativo ético, teriam de integrar, em suas leis, as múltiplas vozes culturais que emanam do chão latino-americano.
} 
Noli Bernardo Hahn \& Rosângela Angelin: Como pensar o direito na atualidade? Diálogos interdisciplinares e transdisciplinares entre direito, cultura, religião e utopias nos movimentos sociais e culturais

\section{REFERÊNCIAS}

- $\quad$ ALVES, Rubem. Livro sem fim. 2. ed., São Paulo: Loyola, 2002.

- ARENDT, Hannah. A condição humana. 10. ed., Rio de Janeiro: Forense Universitária, 2007.

- BÍBLIA, Português. Bíblia Sagrada. 34. ed. Tradução: Centro Bíblico Católico. São Paulo: Paulinas, 2004

- CERVI, Jacson Roberto; HAHN, Noli Bernardo. A terra pede paz - a emergência do paradigma do cuidado e a superação do paradigma da conquista. In: Revista Internacional de Direito Ambiental, Caxias do Sul: Plenum, n. 15, p. 95-116, set/dez 2016.

- CROATTO, José Severino. Hermenêutica bíblica. Rio de Janeiro: Vozes, 1984

- DERRIDA, Jacques; VATTIMO, Gianni (org.). A religião. São Paulo: Estação Liberdade, 2000.

- DERRIDA, Jacques. Torres de Babel. Belo Horizonte: UFMG, 2006.

- DERRIDA, Jacques. O animal que logo sou. São Paulo: UNESP, 2002.

- DERRIDA, Jacques. A farmácia de Platão. 3. ed. São Paulo: lluminuras, 2005.

- DERRIDA, Jacques. A escritura e a diferença. São Paulo: Perspectiva, 2002.

- EISLER, Riane. Cálice e a Espada - nosso passado, nosso futuro. Rio de Janeiro: Imago editora, 1990.

- GADAMER, Hans-Georg. Verdade e método: traços fundamentais de uma hermenêutica filosófica. Petrópolis, RJ: Vozes, 1998.

- GHIRALDELLI JUNIOR, Paulo. O corpo - Filosofia e educação. São Paulo: Ática, 2007.

- HAHN, Noli Bernardo. Jackes Derrida: este que pensou desconstruções. In: OLIVEIRA JÚNIOR, José Alcebíades (org.). Faces do multiculturalismo: teoria, política, direito. Santo Ângelo: Ediuri, 2007, p. 185-197.

- HAHN, Noli Bernardo. A afirmação do sujeito (de direitos) num processo de resistência: A emergência do sujeito humano como liberdade e como criação. In: FALCÃO, Clóvis Marinho de Barros; CESAR, Constança Terezinha Marcondes. Filosofia 
Noli Bernardo Hahn \& Rosângela Angelin: Como pensar o direito na atualidade? Diálogos interdisciplinares e transdisciplinares entre direito, cultura, religião e utopias nos movimentos sociais e culturais

do Direito. Florianópolis: XXIV Encontro Nacional do CONPEDI - UFS, 2015, p. 4-18. Disponível em: http://www.conpedi.org.br/publicacoes/c178h0tg/x552ze4o/J3dKsyN1voll4zYs>. Acesso em: 17 abr. 2017.

- HeIDEgGeR, Martin. Ser e Tempo. 10. ed., Petrópolis: Vozes; Bragança Paulista: Editora Universitária São Francisco, 2016.

- LARAIA, Roque de Barros. Cultura: um conceito antropológico. 18. ed., Rio de Janeiro: Jorge Zahar Editor, 2005.

- MATURANA, Humberto. Prefácio. In: EISLER, Riane. Cálice e a Espada - nosso passado, nosso futuro. Rio de Janeiro: Imago editora, 2007.

- MERLEAU-PONTY, Maurice. A união da alma e do corpo em Malebranche, Biran e Bergson. Belo Horizonte: Autêntica, 2016.

- MORIN, Edgar,. A cabeça bem-feita: repensar a reforma, reformar o pensamento. 16. ed. Rio de Janeiro: Bertrand Brasil, 2009.

- MORIN, Edgar; ALEXANDRE, Maria D.; DÓRIA, Maria Alice Sampaio. Ciência com consciência. Rio de Janeiro: Bertrand Brasil, 1996.

- MORIN, Edgar. O desafio do século XXI: religar os conhecimentos. Lisboa: Instituto Piaget, 2001.

- MORIN, Edgar; PENA-VEGA, Alfredo. O pensar complexo: Edgar Morin e a crise da modernidade. 2. ed. Rio de Janeiro: Garamond, 1999.

- MO SUNG, Jung; SILVA, Josué Cândido da. Conversando sobre ética e sociedade. 9. ed., Petrópolis: Vozes, 2001.

- PAPA Francisco. Carta Encíclica Laudato Si’. Sobre o cuidado da casa Comum. Roma: Tipografia Vaticana, 2015.

- RUEDELL, Aloísio. Hermenêutica - Da necessidade de interpretar para um modo de pensar. ljuí: Unijuí, 2016.

- SCHLEIRMACHER, Friedrich. Hermenêutica e Crítica. Vol. I, Tradução de Aloísio Ruedell e Revisão de Paulo R. Schneider, ljuí: Unijuí, 2005.

- SOBRINO, Jon. Cristologia a partir da América Latina. Petrópolis: Vozes, 1983. 
Noli Bernardo Hahn \& Rosângela Angelin: Como pensar o direito na atualidade? Diálogos interdisciplinares e transdisciplinares entre direito, cultura, religião e utopias nos movimentos sociais e culturais

- TOURAINE, Alain. O mundo das mulheres. Petrópolis: Vozes, 2007.

- TOURAINE, Alain. Um novo paradigma para compreender o mundo de hoje. Petrópolis: Vozes, 2005.

- TOURAINE, Alain. A busca de si. Rio de Janeiro: Bertrand Brasil Ltda, 2004.

- TOURAINE, Alain. Crítica da modernidade. 7.ed. Petrópolis: Vozes, 2002.

- TOURAINE, Alain. Poderemos viver juntos? Petrópolis: Vozes, 1998.

- STOERIG, Hans Joachim. História geral da Filosofia. Petrópolis: Vozes, 2008. 